\section{Promotionspreis 2014 - Ausschreibung}

Die Deutsche Gesellschaft für Ultraschall in der Medizin (DEGUM) vergibt einen Preis für eine hervorragende Dissertation auf dem Gebiet des medizinischen Ultraschalls. Der Promotionspreis ist mit $€ 2000$,- dotiert und kann geteilt werden.

Für den DEGUM-Promotionspreis können Dissertationen berücksichtigt werden, die nach dem 30.6.2011 von einer deutschen Medizinischen Fakultät angenommen wurden. Die Arbeit sollte in der Regel publiziert oder zur Publikation angenommen sein. Hierbei sollte der Bewerber als Erstautor oder als geteilter Erstautor gelistet sein. Die Zustimmung des Betreuers der Arbeit zur Bewerbung wird vorausgesetzt.

Die Bewerbung ist auf elektronischem Weg bis zum 31.05.2014 an die DEGUMGeschäfts-stelle zu richten. Der Bewerbung sind, in digitaler Form (PDF-Datei) und ebenfalls auf elektronischem Weg, die Dissertation und, sofern verfügbar, die akzeptierte Publikation beizufügen.

Der Wissenschaftsbeirat der DEGUM bewertet die Arbeit auf der Grundlage von zwei Gutachten und entscheidet über die
Preisvergabe, seine Entscheidung ist endgültig und nicht anfechtbar.

Die Preisverleihung erfolgt während des Dreiländertreffens 2014 in Innsbruck (29.-31.10.2014). Die persönliche Anwesenheit der Preisträgerin/des Preisträgers ist obligat. Von ihr/ihm wird erwartet, dass sie/er die mit dem DEGUM-Preis ausgezeichnete Arbeit während des Dreiländertreffens in Form eines Vortrags vorstellt. Die Preisträgerin/der Preisträger ist Gast der DEGUM, ihre/seine Reise- und Übernachtungskosten sowie die Teilnahmegebühr werden übernommen.

München im Januar 2014

Dr. S. Nöldeke, Präsident der DEGUM

Prof. Dr. M. Görtler, Sekretär der DEGUM 